\title{
Sarcoma sinovial monofásico primario pulmonar
}

\section{Primary pulmonary synovial sarcoma}

\author{
Leonidas Carrillo-Ñañez,' Pamela Carrillo-García, \\ Stephanie Palacios-Ramirez,, ${ }^{3}$ César Chiang-García ${ }^{4}$
}

Carrillo-Ñañez L, Carrillo-García P, Palacios-Ramírez $\mathrm{S}$, Chiang-García C. Sarcoma sinovial monofásico primario pulmonar. Rev Soc Peru Med Interna. 2019; 32(3):99-102.

https://doi.org//0.36393/spmi.v32i3.476/

\begin{abstract}
RESUMEN
Paciente de 73 años, admitido por dolor torácico, tos no productiva, disnea progresiva, baja de peso y una masa pulmonar heterogénea que ocupaba gran extensión del hemitórax derecho con efusión pleural. El estudio histopatológico demostró la presencia de neoplasia fusocelular de aspecto mesenquimal con extensas áreas de necrosis y escasa mitosis. El estudio inmunohistoquímico reveló panqueratina, BCL2 y CD99 positivos y desmina negativo; EMA: expresión focal aislada; Ki-67: índice proliferativo elevado, alrededor de $35 \%$. Se planificó inicio de quimioterapia y radioterapia, pero el paciente rehusó el tratamiento.
\end{abstract}

Palabras clave. sarcoma sinovial, neoplasia pulmonar.

\section{ABSTRACT}

a 73 year-old patient was admitted for thoracic pain, nonproductive cough, progressive dyspnea, weight loss and a heterogeneous pulmonary mass which occupied most of right hemithorax and pleural effusion. Histopathologic studies showed the presence of a spindle cell neoplasia with mesenchymal tissue, large necrotic areas and poor mitoses, Inmunohistochemical studies was positive for panqueratine, $B C L 2, C D 99$, and negative for desmin; EMA: isolated focal expression; Ki-67: high proliferative index, near $35 \%$. Although chemoteraphy and radiotherapy was indicated, the patient refused the treatment.

KEYWORDs. synovial sarcoma, pulmonary neoplasia.

\section{INTRODUCCIÓN}

El sarcoma sinovial (SS) primario pulmonar es una neoplasia mesenquimal de células fusiformes, puede surgir del parénquima pulmonar, de la pared de los

I. Médico internista. Facultad de Medicina. Universidad Nacional Mayor de San Marcos. Hospital Nacional Arzobispo Loayza, Lima.

2. Médica geriatra. Madrid, España.

3. Interna. Facultad de Medicina, Universidad San Martín de Porres. Hospital Nacional Arzobispo Loayza, Lima.

4. Médico patólogo. Facultad de Medicina, Universidad Peruana Cayetano Heredia. Hospital Nacional Arzobispo Loayza, Lima. bronquios o de la arteria pulmonar. Principalmente es de localización central, aunque ocasionalmente puede ser periférica, con compromiso bronquial. ${ }^{1,2}$ Es de muy rara presentación, corresponde al $10 \%$ de los sarcomas de partes blandas, los que suelen presentarse principalmente en las extremidades inferiores, y al $0,5 \%$ de todas las patologías malignas pulmonares. ${ }^{3}$

Ocurre tanto en varones como en mujeres, los de localización torácica, por lo general, se presentan en la edad adulta y la edad media al diagnóstico es 38 años. ${ }^{4}$

En $66 \%$ de los pacientes se presentan atelectasia, neumonía posobstructiva y hemoptisis, por ser tumores de localización central. Sin embargo, los de localización periférica usualmente son asintomáticos, pero pueden infiltrar pleura, pared torácica, mediastino, ganglios linfáticos, cerebro, médula espinal y adrenales. ${ }^{5}$

Para el diagnóstico es de utilidad estudios de imágenes como tomografía, biopsia pulmonar, estudio inmunohistoquímico y estudio citogenético. Aunque las características citomorfológicas e inmunohistoquímicas son suficientes para tal fin, la correlación clínica es también esencial para el diagnóstico. ${ }^{6}$ 
Son tumores sensibles en el $24 \%$ al uso de ifosfamida y doxorrubicina, como tratamiento coadyuvante la radioterapia, y en etapas tempranas la cirugía es la indicación. La recidiva local puede ocurrir como infiltración al mediastino, pericardio o pared torácica. ${ }^{6-8}$

El pronóstico de la enfermedad es pobre, aunque algunos estudios muestran que el rango de sobrevivencia a los cinco años se encuentra entre $36 \%$ y $70 \%{ }^{5,9}$

Se presenta un caso de SS primario del pulmón.

\section{PRESENTACIÓN DEL CASO}

Paciente varón de 70 años de edad, mestizo, natural y procedente de Chincha, con instrucción primaria incompleta, trabajó en construcción civil. Fue admitido en el hospital por presentar tres meses de enfermedad, de inicio insidioso, curso progresivo, caracterizado por tos con expectoración inicialmente blanquecina, disnea a medianos esfuerzos, ortopnea y, posteriormente, dolor torácico derecho de moderada intensidad. Al inicio se automedicó, con lo que alivió un poco sus molestias. Un mes antes de su ingreso manifestó tos exigente con poca expectoración, dolor torácico más intenso y disnea a pequeños esfuerzos, tras lo cual a iniciativa de los familiares decidieron realizarle una radiografía de tórax. Al habérseles informado que había un problema pulmonar decidieron acudir a un hospital de donde fue referido a este hospital. En los días previos presentó sensación de alza térmica, mayor dificultad respiratoria, dolor torácico de mayor intensidad, pérdida de unos $10 \mathrm{~kg}$ de peso, sudoración nocturna y sensación de llenura precoz.

Antecedentes: hipertensión arterial desde hace cinco años, tratamiento con captopril; operado de hernia inguinal izquierda hace ocho años; apendicectomía y resección intestinal de $10 \mathrm{~cm}$; colocación de malla por hernia umbilical. Antecedentes epidemiológicos no contributorios.

\section{Examen físico}

Presión arterial 100/70 mmHg; frecuencia respiratoria $22 \mathrm{rpm}$; frecuencia cardíaca $92 \mathrm{lpm}$; temperatura $37{ }^{\mathrm{a}} \mathrm{C}$, saturación de $\mathrm{O}_{2} 94 \%$. Paciente en aparente regular estado general, buen estado de hidratación, regular estado de nutrición, adelgazado con palidez de piel y mucosas, no cianosis, palmas de manos eritematosas, con pequeñas máculas hiperpigmentadas. Se evidencia ganglio cervical derecho único, móvil no doloroso de $2 \times 2 \mathrm{~cm}$, no adherido a planos profundos.
Pulmones: taquipneico sin uso de músculos accesorios. Tráquea ligeramente desviada a la izquierda, disminución de la expansión del hemitórax derecho con presencia de circulación colateral, ausencia de vibraciones vocales, matidez y abolición del murmullo vesicular en todo el hemitórax derecho.

Abdomen: no asimetría, ruidos hidroaéreos presentes, blando, depresible, ausencia de dolor, de visceromegalia y de masas palpables. Extremidades: no edemas. Neurológico: semiológicamente normal.

\section{Exámenes auxiliares}

Hemograma normal; creatinina $1,06 \mathrm{mg} / \mathrm{dL}$, urea $51 \mathrm{mg} / \mathrm{d} ;$ PCR $4,2 \mathrm{mg} / \mathrm{dL}$. Tiempo de protrombina 15,4 s; pruebas hepáticas normales. Sodio $131 \mathrm{mEq} / \mathrm{L}$.

CYFRA 21-1, CEA, alfa-fetoproteína, CA19-9 y PSA total dentro de valores normales.

Radiografía de tórax: desviación del mediastino hacia el lado izquierdo, obturación de los senos costofrénico y cardiofrénico derechos, masa en tercio superior de pulmón derecho de aspecto tumoral, heterogéneo; no se define borde cardiaco derecho (Figura 1).

TEM: pulmón derecho con imagen de aspecto tumoral, con componente quístico y sólido, que capta contraste, de contornos nodulares, de $235 \mathrm{~mm}$ x $149 \mathrm{~mm}$, que ocupa los segmentos de los lóbulos superior e inferior hasta el mediastino superior y posterior (Figura 2).

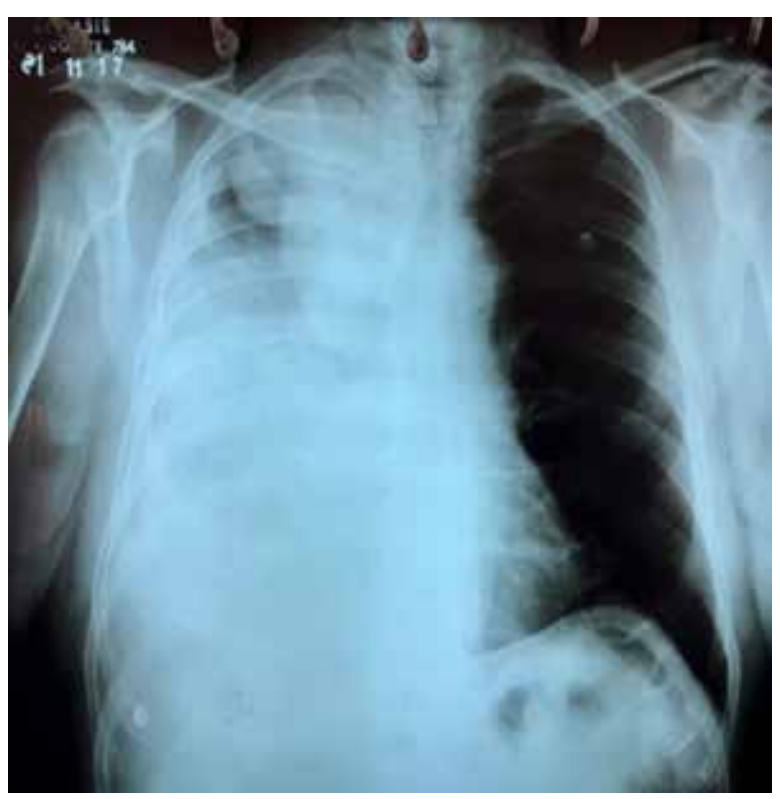

Figura I.Tumor heterogéneo. No se define el borde cardíaco, efusión pleural extensa. 


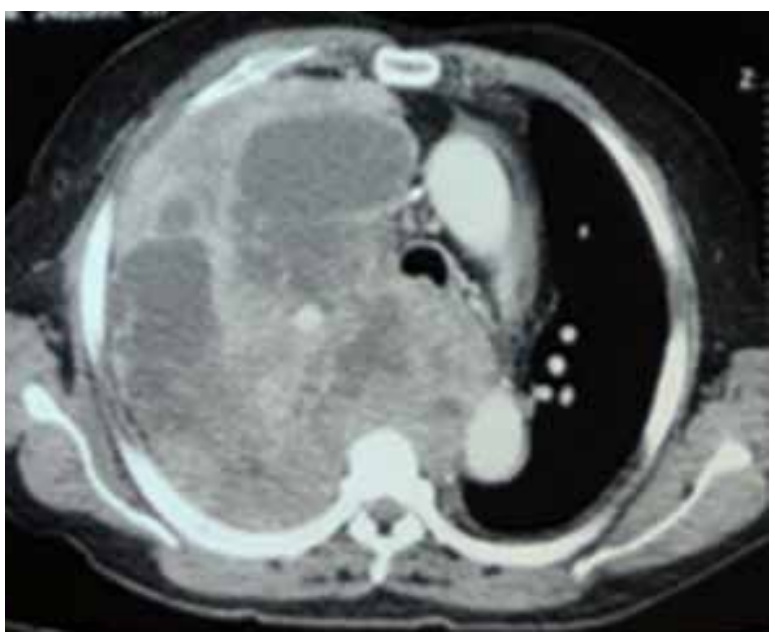

Figura 2. Tumor con componente quístico y sólido. Capta contraste, con extensión a mediastino.

Biopsia de ganglio por aspiración con aguja fina: ocasionales células de aspecto epitelial, adipocitos, hematíes y material fibrinoide.

Biopsia pleural y pulmonar por minitoracotomía: neoplasia fusocelular de aspecto mesenquimal con extensas áreas de necrosis y escasas mitosis (Figura 3); pared del tumor: tejido fibroso infiltrado por neoplasia mesenquimal de similares características al anterior; tejido pleural: tejido fibroso infiltrado por neoplasia mesenquimal de similares características a las descritas (Figura 4).

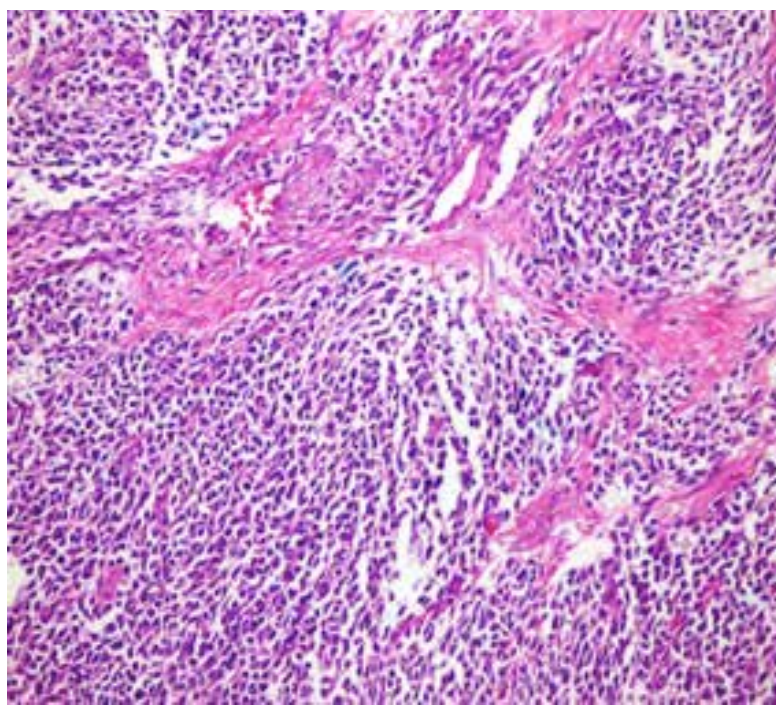

Figura 3. Infiltración fusocelular de aspecto acompañada de extensas áreas de necrosis, escasas mitosis.

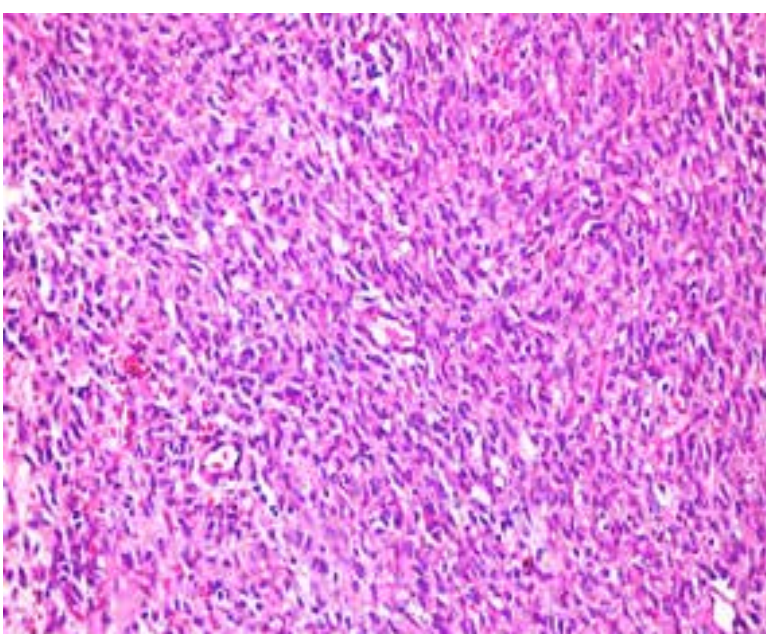

Figura 4. Tejido fibroso infiltrado por neoplasia mesenquimal.

Estudio inmunohistoquímico: panqueratina, BCL2 y CD99 positivos, desmina negativo. EMA (antígeno epitelial de membrana): expresión focal aislada. Ki-67: índice proliferativo elevado, alrededor $35 \%$. El inmunofenotipo es compatible con SS monofásico.

\section{Interconsultas}

Fueron realizadas a las siguientes especialidades: neumología (biopsia pulmonar percutánea); cirugía de cabeza y cuello (punción por aspiración de ganglio cervical); cirugía de de tórax y cardiovascular (biopsia por minitoracotomía); oncología.

Biopsia pulmonar: pleura engrosada de $5 \mathrm{~mm}$ con tejido blando cerebroide, sangrante, tumoración encapsulada dependiente del lóbulo inferior derecho con contenido hemático de aproximadamente $1500 \mathrm{~mL}$, gran cantidad de tejido cerebroide grumosa, sangrante con coágulos. Se resecó $70 \%$, quedó una cavidad muy friable, se colocó un dren de la pared a la cavidad tumoral.

Servicio de oncología: tres evaluaciones hechas con los resultados obtenidos, plantea diagnóstico de SS monofásico pulmonar primario estadio clínico $\mathrm{IV}$; presenta plan para el retiro de quimioterapia y radioterapia.

\section{DISCUSIÓN}

El SS, según su histopatología, se clasifica en los subtipos bifásico, monofásico fibroso, monofásico epitelial y pobremente diferenciado. La forma más común es el SS subtipo monofásico. ${ }^{10,11}$ 
Las principales manifestaciones del caso que se presenta fueron tos escasamente productiva, dolor torácico, disnea progresiva y pérdida ponderal. No hubo hemoptisis a falta de una erosión de la pared bronquial, a pesar de un importante contenido de material sanguinolento encontrado dentro del tumor, donde además se observó gran necrosis, alteraciones que han sido reportadas. ${ }^{12}$

La masa tumoral de aspecto heterogéneo ocupaba gran parte del hemitórax derecho, acompañada de gran efusión pleural, desplazaba el mediastino hacia el lado izquierdo y lo infiltraba. El SS pulmonar es un tumor muy agresivo, no se ha descrito ningún cambio radiológico característico y, a menudo, es confundido con carcinoma broncogénico. ${ }^{13}$

El SS primario pulmonar en su estadio temprano puede que no se presente síntomas y cuando se encuentra en estadios avanzados, como en el paciente de este caso, son comunes los síntomas poco específicos como los ya mencionados y, además, efusiones pleural y pericárdica.

No se han descrito hallazgos de laboratorios característicos en el SS pulmonar, incluidos los marcadores tumorales comunes.

Los principales diagnósticos diferenciales según los hallazgos histopatológicos se hacen con otras neoplasias de células fusiformes como fibrosarcoma, hemangiopericitoma, leiomiosarcoma y carcinosarcoma..$^{14,15}$

La importancia del estudio inmunohistoquímico radica en la determinación del subtipo. Así, se han descrito una serie de marcadores, la mayoría de los SS son positivos para citoqueratinas y/o EMA. La vimentina se expresa generalmente en las porciones de células fusiformes de la neoplasia, y la reactividad S-100 puede identificarse en hasta $30 \%$ de los tumores; BCL-2 y CD99 son frecuentemente positivos; CD34 es generalmente negativo. ${ }^{14}$ En el paciente del presente caso, se encontró lo siguiente: panqueratina, BCL2 y CD99 positivos; desmina negativo; EMA, expresión focal aislada; Ki67 , índice proliferativo elevado, alrededor $35 \%$, es el inmunofenotipo más compatible con SS monofásico.

El estudio de citogenética es determinante, aunque no se realizó en el paciente del presente caso. Se ha descrito la translocación $\mathrm{t}(\mathrm{x} ; 18)$ en $92 \%$ de casos. El estudio citogenético por reacción en cadena de la polimerasa en tiempo real (RT-PCR) ayuda a diferenciar la forma monofásica de la bifásica.

El SS es caracterizado por una translocación cromosómica recíproca $(\mathrm{X} ; 18)$ (p11.2; q11.2) que resulta de la fusión del gen $S Y T$ en el cromosoma 18 a cualquiera de los dos genes SSX 1 y SSX 2 en el cromosoma X. El gen SYT-SSX 1 es asociado con el subtipo bifásico y el pronóstico es malo. Mientras que el subtipo monofásico puede tener cualquiera de dos transcripciones de fusión, SYT-SSX 1 o SYT-SSX 2. Todos los tumores con el gen SYT-SSX 2 muestran morfología monofásica. A pesar de su alta sensibilidad, las pruebas moleculares no son requeridas si el diagnóstico de SS es seguro o probable sobre la base clínica, histológica y evaluaciones inmunohistoquímicas. ${ }^{14}$

En conclusión, el SS primario pulmonar es muy raro en pacientes adultos mayores, y su diagnóstico requiere estudios de imagen, citomorfológico, inmunohistoquímico y citogenético. No es de buen pronóstico y tiene pobre respuesta al tratamiento.

\section{REFERENCIAS BIBLIOGRÁFICAS}

I. Weiss S. Histological typing of soft tissue tumors. 2nd ed. LH S, editor. Berlin: Springer Verlag; 1994.

2. Mankin $\mathrm{H}$, Hornicek F. Diagnosis, classification and management of soft tissue sarcomas. Cancer Control. 2005; I2:5-2I

3. Spraker M, Bair E, Bair R, Connell P, Mahmood U, Koshy M. An analysis of patient characteristics and clinical outcomes in primary pulmonary sarcoma. J Thorac Oncol. 2013;8:147-I5I.

4. Gladish G, Sabloff B, Munden R, Truong M, Erasmus J, Chasen M. Primary thoracic sarcomas. Radiographics. 2002;22:621-37.

5. Etienne-Mastroianni B, Falchero L, Chalabreysse L, Loire R, Ranchère $D$, Souquet $P$, et al. Primary sarcomas of the lung: A clinicopathologic study of 12 cases. Lung Cancer. 2002;38:283-9.

6. Cabuk D, Ustuner B, Akgul AG, Acikgoz O, Yaprak B, Uygun K, et al. Primary synovial sarcoma of lung. Korean J Thorac Cardiovasc Surg. 2014;47:306-309.

7. Dennison S,Weppler E, Giacoppe G. Primary pulmonary synovial sarcoma: a case report and review. Curr Diagn Therap Stand. 2004;9:339-342.

8. Spillane A,A Hern R, Judson I, et al. Synovial sarcoma:A clinicopathologic, staging and prognostic assessment. J Clinic Oncol. 2000; 18:3794-3803.

9. Hartel P, Fanburg-Smith J, Frazier A, Galvin J, Lichy J, Shilo K, et al. Primary pulmonary and mediastinal synovial sarcoma clinicopathologic study of 60 cases and comparison with five prior series. Mod Pathol. 2007;20:760-9.

10. Okamoto S, Hisaoka M, Daa T, Hatakeyama K, Iwamasa T, Hashimoto H, et al. Primary pulmonary synovial sarcoma:A clinicopathologic, immunohistochemical, and molecular study of II cases. Hum Pathol. 2004;35:850-6.

II. Essary L, Vargas S, Fletcher C. Primary pleuropulmonary synovial sarcoma: Reappraisal of a recently described anatomic subset. Cancer. 2002;94:459-69.

12. Gaertner E, Zeren E, Fleming M, et al.. Biphasic Synovial sarcomas arising in the pleura cavity: a clinicopathologic study one five cases. Am J Surg Pathol. 1996;20:36-45.

13. Bhattacharya D, Datta S, Das A, Halder KC, Chattopadhyay S. Primary pulmonary synovial sarcoma:A case report and review of literature. Int J Appl Basic Med Res. 2016;6(I):63-65.

14. Frazier AA, Franks TJ, Pugatch RD, Galvin JR. The archives of the AFIP pleuropulmonary synovial sarcoma. Radiographics. 2006;26(3):923-40.

15. Mermigkis CM, Kopanakis A, Patentalakis G, Polychronopoulos V, Patentalakis M. Pimary monophasic synovial sarcoma presenting as a pulmonary mass: a case report.J Med Case Reports. 2008;2:18.

CoRRESPONDENCIA: Leonidas Carrillo-Ñañez Ichcarn@yahoo.es

FECHA DE RECEPCIÓN: 23 de mayo de 2019.

FECHA DE ACEPTACIÓN: I5 de julio de 2019. 